UDC 94(495).01

Submitted: 19.03.2018

LBC 63.3(0)32

Accepted: 28.09.2018

\title{
TO THE QUESTION OF SOURCES AND INFLUENCES IN CYRIL OF SKYTHOPOLIS' WORKS
}

\author{
Yuliya V. Sheludchenko \\ Belgorod State National Research University, Belgorod, Russian Federation \\ Nikolay N. Bolgov \\ Belgorod State National Research University, Belgorod, Russian Federation
}

\begin{abstract}
Introduction. Cyril of Scythopolis (524 - after 559) is one of the most famous early Byzantine hagiographers, the most important source on the history of the Palestinian monastery of the Judean Desert of the $6^{\text {th }}$ century AD. The preserved lives of Saints, despite a high degree of originality, have well-established sources.

Methods. The methodological basis of the work is the conception of Late Antiquity in the spirit of the continuum, as part of the theory of local civilizations. The historical and biographical (relative to the person of Cyril) methods and the method of content analysis (regarding the content of sources) have also been used.

Analysis. The sources can be divided into literary, documentary, oral and autobiographical. The works of Cyril do not show us the knowledge of classical, non-Christian works. By this, Cyril of Scythopolis is different significantly from the majority of writers of late Antique time. Cyril was not the only monk of the $6^{\text {th }}$ century Palestine who wrote about the saints. Nevertheless, it is the lives written by Cyril of Scythopolis that give us the most vivid picture of the monastic life of the $6^{\text {th }}$-century Palestine, especially the Judean Desert. Cyril's sources were diverse, and their use allows us to conclude that a reasonable degree of borrowing does not distort the reliability of most of the historical information reported. Cyril is a very accurate historian and a connoisseur of Palestine, and his religiosity is not at all original, but typical, never embellishing what he saw. $\mathrm{He}$ is full of naive prejudices, but never burdens his compositions with fabulous details. Therefore, it is an important source not only for the history of the church and monasticism, but also for the whole history of Early Byzantium.
\end{abstract}

Results. Sources of Cyril are quite diverse, and their use allows us to make conclusion about a reasonable degree of borrowing, not distorting the reliability of most of the reported historical information.

The authors of the article have divided the research tasks in the following way: the analytics and the main conclusions have been prepared by Yu.V. Sheludchenko; N.N. Bolgov has worked with Greek originals, specifying terms and categories and carried out general editof the text.

Key words: Late Antiquity, Early Byzantium, Cyril of Scythopolis, lives of Saints, monastic tradition, sources.

Citation. Sheludchenko Yu.V., Bolgov N.N. To the Question of Sources and Influences in Cyril of Skythopolis' Works. Vestnik Volgogradskogo gosudarstvennogo universiteta. Seriya 4, Istoriya. Regionovedenie. $\infty$ Mezhdunarodnye otnosheniya [Science Journal of Volgograd State University. History. Area Studies. International 굴 Relations], 2018, vol. 23, no. 5, pp. 169-178. (in Russian). DOI: https://doi.org/10.15688/jvolsu4.2018.5.15

\section{К ВОПРОСУ ОБ ИСТОЧНИКАХ И ВЛИЯНИЯХ В СОЧИНЕНИЯХ КИРИЛЛА СКИФОПОЛЬСКОГО}

\author{
Юлия Викторовна Шелудченко \\ Белгородский государственный национальный исследовательский университет, \\ г. Белгород, Российская Федерация
}




\section{Николай Николаевич Болгов}

Белгородский государственный национальный исследовательский университет, г. Белгород, Российская Федерация

Аннотация. Кирилл Скифопольский (524 - после 559 г.) - один из крупнейших ранневизантийских агиографов, важнейший источник по истории палестинского монашества Иудейской пустыни VI века. Сохранившиеся написанные им жития святых, несмотря на высокую степень оригинальности, имеют достаточно хорошо устанавливаемые источники. Их можно разделить на литературные, документальные, устные и автобиографические. Сочинения Кирилла не показывают нам серьезного знания им классических, нехристианских произведений. Этим Кирилл Скифопольский значительно отличается от большинства писателей позднеантичного времени. Кирилл не был единственным монахом Палестины VI в., который писал о святых. Тем не менее, именно жития, написанные им, дают нам наиболее яркую картину монашеской жизни Палестины VI в., особенно Иудейской пустыни. Источники Кирилла были разнообразны, а их использование позволяет сделать вывод о разумной степени заимствования, не искажающей достоверность большинства сообщаемых исторических сведений. Кирилл - очень точный историк и знаток Палестины, в своей религиозности совершенно не оригинальный, а типичный, никогда не приукрашивающий увиденное. Он полон наивных предрассудков, но никогда не отягощает свои сочинения сказочными деталями. Поэтому он является важным источником не только по истории церкви и монашества, но и в целом по истории Ранней Византии.

Авторы статьи распределили работу между собой следующим образом: аналитика и основные выводы подготовлены Ю.В. Шелудченко, а Н.Н. Болгов работал с греческими оригиналами источников, уточняя термины и категории. Н.Н. Болгову принадлежит также общее редактирование работы.

Ключевые слова: Поздняя античность, Ранняя Византия, Кирилл Скифопольский, жития святых, монашеская традиция, источники.

Цитирование. Шелудченко Ю. В., Болгов Н. Н. К вопросу об источниках и влияниях в сочинениях Кирилла Скифопольского // Вестник Волгоградского государственного университета. Серия 4, История. Регионоведение. Международные отношения. - 2018. - Т. 23, № 5. - C. 169-178. - DOI: https://doi.org/10.15688/ jvolsu4.2018.5.15

Введение. Кирилл Скифопольский (524 - после 559 г.) [3, с. 320-329] - крупнейший агиограф VI в. - родился и вырос в сугубо церковной среде. Из-за сильного монашеского влияния на церковь в Скифополе и близкого вовлечения семьи Кирилла в дела церкви [4, с. 46-50] жизненный путь Кирилла был в значительной степени предопределен уже с ранних лет. Его сочинения - жития святых монахов Иудейской пустыни - важный памятник агиографии. Поэтому вопрос об источниках, влияниях и заимствованиях в его трудах достаточно интересен прежде всего потому, что Кирилл - один из немногих авторов ранневизантийской эпохи, который практически остался в стороне от классической античной традиции, с которой были хорошо знакомы почти все авторы этого периода.

Методы. Методологической основой работы является концепция Поздней античности в духе континуитета (П. Браун, А. Кэмерон, Ав. Кэмерон и др.), как часть теории локальных цивилизаций. Собственно, используются методы: историко-биографический (от- носительно личности Кирилла) и метод контент-анализа (относительно содержания источников).

Источники. Основным источником по рассматриваемой теме, как и вообще по истории монастырей Палестины, является серия «Житий семи великих монахов пустыни» Кирилла. Первой из этой группы в хронологическом порядке была создана биография Евфимия, который приехал в Иерусалим в 405 г. и умер в 473 году. Он был основателем и настоятелем монастыря на равнине в нескольких милях к востоку от города. Вторым был монах Савва, ученик Евфимия, который прибыл в Иерусалим в 457 г. и вступил в соседнюю киновию (койнобион) Феоктиста. Он продолжил создание нескольких важных монастырей и стал наиболее влиятельной фигурой в церкви в Палестине. Он умер в 532 году. Остальные пять монахов, которые являются героями этих житий - Иоанн Исихаст и Кириак - младшие современники Саввы; Феогний и Феодосий, основатели монастырей; а также Авраам. Этот корпус агиографической пись- 
менности дает почти исчерпывающую картину развития палестинского монашества за полтора века от 400 до 550 г., на которые пришлись Халкидонский собор и его последствия, а также конфликт с оригенизмом, который был осужден на Константинопольском соборе в 553 году [5, p. 23].

В целом Кирилл - очень точный историк и знаток Палестины [11], в своей религиозности совершенно не оригинальный, а типичный, никогда не приукрашивающий увиденное. Он полон наивных предрассудков, но никогда не отягощает свои сочинения невероятными деталями [1, с. 215]. Поэтому он является очень важным источником не только по истории церкви и монашества, но и в целом по истории Ранней Византии. Сочинения Кирилла, вместе с тем, не показывают нам знания им классических, нехристианских произведений. Этим Кирилл Скифопольский значительно отличается от большинства писателей позднеантичного (ранневизантийского) времени.

Сохранившиеся жития святых монахов Иудейской пустыни, написанные им [14; 2 , c. 224-225], имеют достаточно хорошо устанавливаемые источники и тексты, от которых можно установить ту или иную степень влияния или зависимости. Их можно разделить, вслед за Дж. Эллиотт-Биннсом, на литературные, документальные, устные и автобиографические [9].

Анали 3. Литературные источники. Сам Кирилл неоднократно упоминает в качестве своего источника, пусть и вторичного, предания египетской монашеской традиции. Он, в частности, описывает, что «старцы из

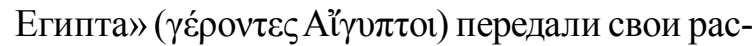
сказы Евфимию (герою одного из «Житий» Кирилла), который использовал их в своей монашеской практике в Иудейской пустыне. Здесь явно видна параллель между борьбой Саввы с демонами и теми же эпизодами у Антония Египетского (демон «явился великому Антонию, и показал себя также Савве, чтобы дать ему силу»). Уважение, которое палестинские монахи проявляли к Антонию, также показано празднованием его дня в Евфимиевом монастыре. Эти заимствования не просто обнаруживают связь между двумя текстами, но являются признаками более крупного процесса, с помощью которого слова, идеи и истории передава- лись по всему средиземноморскому позднеантичному миру $[12, \mathrm{p} . \mathrm{XX}]$.

Зависимость Кирилла от предшествующих ему агиографических сочинений обычно считается значительной и системной [9]. Однако такие сходства являются зачастую общими местами агиографических сочинений, связаны со стереотипностью и формульностью, и поэтому не могут служить для установления прямой текстуальной зависимости. Но Дервас Читти показал важность исследования этих литературных взаимосвязей: «В работах Кирилла использованы целые пласты цитат из более ранних работ такого же рода Vita Antonii, Vita Pachomii, Apophthegmata Patrum и т. д.» [6, p. 131].

Дж. Эллиотт-Биннс насчитывает свыше 120 мест, где, по всей вероятности, Кирилл что-то заимствовал или находился под прямым влиянием работы более раннего автора агиографической традиции. Видимо, эти сведения неполны.

Литературная и текстуальная связь, которая, как минимум, достаточно хорошо рассмотрена в историографии - это связь между Кириллом и Палладием Еленопольским, автором «Лавсаика». Может показаться удивительным, что Кирилл мог знать и использовать сочинение Палладия, откровенного сторонника Евагрия Понтийского ${ }^{1}$, но есть несколько отрывков, которые явно показывают такую зависимость ${ }^{2}$. Р. Драгье перечисляет девять параллельных отрывков, свидетельствующих о зависимости текста Кирилла от текста Палладия. Этот список не вполне убедителен. Дж. Эллиотт-Биннс считает точно установленными три отрывка, один рассматривает как сомнительный и пять - как недостаточно доказуемые, чтобы употребляться как свидетельство зависимости [9, р. 45]. Из трех убедительных и признанных ссылок две происходят от Палладиевой главы о Макарии Египетском, и обе встречаются в одном и том же разделе сочинения Кирилла (Kyr. 78.12-13; 79.6-8 - нумерация по изданию Шварца [14]). Поэтому, скорее всего, Кирилл использовал «Лавсаик» не целиком, но лишь какие-то конкретные главы и пролог. Эти списки параллелей могут быть расширены, что обнаруживает большее влияние Палладия на Кирилла, чем считалось ранее. 
Также интересно отметить, какие работы Кирилл не использовал (argumentum ex silentio). Например, «Житие Порфирия» Марка Диакона, написанное в начале V в. в Газе, и «Житие Мелании» Геронтия, написанное в конце V в. в Иерусалиме, должны были быть доступными для Кирилла, но никаких признаков, что он использовал эти книги, нет.

Особенности использования фраз обнаруживают, что Кирилл, по всей видимости, знал «Житие Антония», но не знал Historia Monachorum.

Заимствования Кирилла из разных авторов различаются по природе заимствования. Во-первых, есть случаи, когда Кирилл просто копировал отрывок. Таковыми признаны лишь две цитаты, обе из сочинений Григория Назианзина. Первая - сравнение между молодым Василием и царем Давидом, которое Кирилл применяет к Евфимию (Kyr. 12.2). Вторая является введением к дискуссии с мнениями оригенистов (Kyr. 229.27-28; cp. Greg. Naz. Or. 2.1). Техника заимствования здесь представляется простой: Кирилл, видимо, имел текст перед собой и копировал из него фразы или целые предложения. Его использование этих авторов ограничено специфичными фразами, которые он заимствовал, и он здесь, видимо, не использовал общий словарь, отдельные истории или богословские мнения.

Пример автора, используемого этим же способом, - Нил Анкирский. Кирилл копировал из его De Monastica exercitatione 4 раза, два из которых имеются в его Прологе к «Житию Евфимия», и два в отрывке, описывающем добродетели Саввы (Kyr. 78.18-24). Других примеров заимствования из Нила нет. Представляется, что Кирилл был поражен суждением Нила о лидерстве внутри монашеской общины и вставил только этот элемент. «Житие и чудеса Феклы» Василия Селевкийского также использованы этим способом. Все эти авторы происходят из Сирии или Малой Азии.

Использование Кириллом «Церковной истории» Феодорита Кирского - более сложное и комплексное. Число параллельных отрывков здесь больше - 19 - и хотя они включают явные случаи прямого копирования, есть признаки того, что здесь речь идет не просто о копировании, но и о том, что понимание Фе- одоритом духовной жизни также оказало влияние на Кирилла. В частности, концепция $\pi \alpha \rho \rho \eta \sigma i ́ \alpha$ (откровения) как цели аскетического поведения заимствована Кириллом частично из Феодорита. Уважение, которое Кирилл испытывал к сочинению Феодорита, показано пропуском имени Феодорита в сообщении Кирилла о богословах, анафематствованных на Соборе 553 г. в Константинополе (Kyr. 119.3-6). По сути, Феодорит был одним из основных источников Кирилла, с которым он работал наиболее активно. Можно заключить, что литература Сирии и Малой Азии главным образом использовалась Кириллом как источник цитат, которые он прямо копировал.

Вторая форма влияния менее четко выражена и, соответственно, может быть менее четко установлена. Это параллели, отражающие более общие мысли и идеи. Они иллюстрируются обращением Кирилла к египетским источникам. Эти параллели не являются примерами близкого словесного сходства, которое могло быть результатом простого копирования. Параллельные отрывки - гораздо более многочисленные и разнообразные. Они включают случаи, где использовалась сходная стереотипная фраза, подобная той, что монахи «превратили пустыню в город»

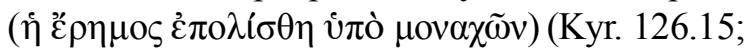
158.17-18; cp. V. Ant. 14). Говоря об аспектах монашеских правил, Кирилл использует рассказ из Apophthegmata patrum, чтобы проиллюстрировать харизматический дар распознавания духов (Kyr. 37.1-20). Аскетические добродетели египетской пустыни использованы как источник описания руководства для палестинского святого, особенно в сравнении Арсения и Евфимия (Kуr. 34.17-24). Порой Кирилл составляет целую часть текста, основываясь на египетском источнике, как в случае, когда Пролог «Жития Евфимия» базируется на фрагменте «Жития Пахомия», описывающего, как аскеты верны традиции христианского свидетельства о вере, ведущего начало от апостолов и мучеников.

Широта, с которой египетские аскетические традиции проникают в Иудейскую пустыню, едва ли может быть недооценена. Apophthegmata patrum активно читались в Палестине IV-V веков. Если более короткие собрания монашеских текстов по отдельным 
вопросам содержат лишь высказывания, приписываемые египетским монахам, то систематические и алфавитные коллекции содержат также рассказы о палестинских монахах. Поэтому имеется сильный соблазн предположить, что первая коллекция алфавитно-анонимного типа была сформирована в Палестине, а не в Египте [13, p. 328].

Третья форма влияния обнаруживает себя в повествовательном стиле Кирилла. Предыдущие два типа влияния касаются содержания сочинений Кирилла. Это же влияние ощущается в форме. Прежде всего речь идет о стилистических заимствованиях из Библии, как, например, следует из сравнения описания Кириллом пастухов, наблюдающих победу Саввы над демонами на холме Кастеллион (Castellion), и хорошо известного отрывка о пастухах, рассказавших о рождении Иисуса.

Знание Кириллом Библии оказало влияние на его стиль и оформило способ, которым он рассказывает свои истории. Многие другие места его сочинений напоминают нам отрывки из Библии. Это и исцеление Саввой кровотечения у женщины, и чудесное окормление толпы четырехсот, и др. (Kyr. 163.23164.10, ср. Деяния.3.6; Матф. 9.22. 27.5-28.8; 2 Царств 7.14; 4.44; 7.14; Матф. 15.37; 2 К Коринфянам 9.6; К евреям 13.2; последние два цитируются прямо).

Можно сделать вывод о том, что Кириллов нарратив зависит от агиографической литературы практически в той же мере, что и от Библии.

Влияние литературных источников на Кирилла проявляется более ощутимо в некоторых разделах его сочинений. «Житие Евфимия», которое короче, чем «Житие Саввы», содержит наибольшее число заимствований. Кирилл писал это первое «Житие» где-то около 553 года. К тому времени Евфимий уже 80 лет как умер (в 473 году. См.: Kyr. 59.22-60.8). Из информаторов Кирилла только Кириак, который умер в 556 или 557 г. в очень почтенном возрасте 107 лет, действительно знал Евфимия ${ }^{3}$, и даже имел с ним самое краткое личное знакомство. В своей информации о Евфимии Кирилл полагался на устную традицию более, чем на сообщение очевидца. В отсутствии исторических свидетельств Кирилл чер- пал из монашеских источников материал для построения своей картины личности и жизни святого. Распределение заимствований между обеими работами показывает, что он использовал письменные источники из монашеской традиции тогда, когда ему не хватало устных источников.

Распределение заимствований внутри работ приводит к выводу о характере использования источников Кириллом. Заимствования встречаются внутри двух категорий материала. Во-первых, Кирилл полагается на письменные источники в составлении своего вводного пролога. Его введение к «Житию Евфимия» составлено на основе Пролога к «Житию Пахомия», а также на двух цитатах из Нила Анкирского и одной из «Чудес Феклы». Пролог к «Житию Саввы» содержит две длинные цитаты из «Чудес Феклы» (Kуг. 85.1286.26). Кирилл начинает свои «Жития» с заботливо сконструированных прологов, которые основываются на более ранних работах как по структуре, так и по характеру составления определенных разделов.

Второе и главное использование Кириллом текстов сочинений более ранних писателей имеет место в качестве источника для его разделов об аскетическом учении. Выражение личных религиозных чувств Кирилла поэтому мало оригинально. Это мнение подтверждается, когда мы понимаем, как широко он опирался на других авторов в своем составлении наиболее значимых пассажей. Аскетическое учение Кирилла содержится главным образом в «Житии Евфимия» (Kyr. 17.418.11). Этот короткий раздел состоит из двух ссылок на «Житие Пахомия», двух - на «Житие Антония» и двух - на «Церковную историю» Феодорита. Указание монахам, решившим покинуть монастырь, ссылается главным образом на Apophthegmata patrum (5-й раз), но также и на «Лавсаик» Палладия (Kyr. 29.27-32.5).

Другие отрывки, которые присутствуют или в дискурсе об аскетическом учении, или в описаниях аскетических достижений святого, и которые используют другие работы как источники - это сравнение Евфимия с Арсением - под влиянием Apophthegmata Patrum (Kyr. 34.1-30); история Эмилиана, представляющая Евфимиев дар проницательности - под влиянием «Жития Антония» и Apophthegmata 
Patrum (Kyr. 34.1-30); аскетическая борьба Саввы - под влиянием «Жития Пахомия» и Нила Анкирского (Kyr. 99.5-101.5); история обнаружения Саввой анахорета в пещере - под влиянием Apophthegmata Patrum (Kyr. 107.23109.2); борьба Саввы против демонов на холме Кастеллион, которая сравнивается с такой же борьбой Антония - под влиянием «Жития Антония» (Kyr. 110.1-111.5). Более чем половина всех заимствований Кирилла из монашеских источников находится в относительно немногих отрывках, которые составляют собственно аскетическое учение или описание аскетического подвига.

Небольшая оригинальность есть в отрывках, которые излагают догматическое учение. Пять главных пассажей, которые содержат доктринальные положения - Пролог к «Житию Евфимия»; отрывок, описывающий рвение Евфимия в борьбе с ересью; Евфимиева защита Халкидонского собора; обращение Саввой двух несторианских монахов; демонстрация Кириаком ошибок оригенизма (Kyr. 6.21-7.15; 39.18-41.3; 229.31-231.19). Эти пассажи содержат положения теологической позиции, которую Кирилл поддерживал. Защита Евфимием Халкидона взята из «Актов Собора». Это цитата из Кирилла Александрийского о том, «что различие в природе не отменено единством», которая находится в «Актах Собора».

Другие отрывки из житий Евфимия и Саввы зависят от теологических сочинений Юстиниана. Есть сходство между Кириллом и четырьмя сочинениями императора:

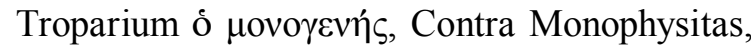
Confessio Fidei, Edictum contra Originem. Из них зависимость от Confessio Fidei наиболее ощутимая. Кирилл этими заимствованиями показывает, что поддерживает теологические позиции, одобренные императором.

Источники по критике оригенизма менее ясны. Есть близкие вербальные параллели с 15-ю анафемствованиями, изданными Собором 553 г., но Кирилл дает дополнительные детали, не содержащиеся в анафемствованиях, - например, о том, что оригенисты верят, что в повторном возвращении душ на землю могла содержаться сила создавать миры [7, S. 88-97]. Если 15 анафемствований отвергнуть в качестве источника Кирилла, то тогда можно заключить, что Кирилл использовал другой документ, который утерян.

Кирилл ссылается еще на три документа, которые могли быть задействованы им как источники. Софроний и Геласий, преемники Феодосия и Саввы, соответственно, составили libellus («книжечку») против оригенистов, которую Петр Иерусалимский отправил в Константинополь (Kуг. 189.13-190.14). Позже некоторые из коллег Кирилла написали опровержение оригенистских сект изохристов и тетрадитов (Kуг. 197.10-13). В частности, Конон, наместник Великой Лавры, адресовал libellus императору Юстиниану (Kyr. 198.14-17). Все это было написано между 543 и 553 гг. и показывает, что документы, нападающие на оригенизм, циркулировали в Палестине во времена, когда писал Кирилл.

Таким образом, при составлении аскетических и доктринальных пассажей Кирилл использовал письменные источники при формулировании своего мнения. Эти обе темы были близко связаны в его представлениях. Эти пассажи могут быть отделены от исторических мест, которые больше зависят от устной традиции.

Документальные источники. Часть целей Кирилла заключалась в том, чтобы показать, что Евфимий и Савва внесли вклад не только в рост монашества в Палестине, но также в благоденствие всей Церкви. Когда Евфимий завершил свое путешествие в Иерусалим и затем поселился в Лавре Фаран, видимо, он более никогда не покидал Иудейскую пустыню (Kуг. 14.3-11). Савва был более активно вовлечен в историю империи, путешествуя в Константинополь и на пространстве всей империи Юстиниана ниспровергая ереси (Kуr. 175.19-176.20). Кирилл не ограничивает свое описание локальной церковной жизнью в Палестине, но описывает места событий в более широком контексте. Он сообщает о соборах в Эфесе и Халкидоне (Kyr. 32.6-33.28; 41.4-45.4), дает обзор политической ситуации, исходя из которой Савва предпринимает свою миссию в Константинополь (Kyr. 139.29-141.23). Вмешательство императора важно для описания первых лет захвата Петром епархии Иерусалима (Kyr. 148.10158.11). Для подготовки этих разделов своего сочинения Кирилл, видимо, имел доступ к 
официальным документам, содержавшимся, как мы можем предположить, в архивах или в Великой Лавре, или в Иерусалиме. Возможно, существовали монастырские архивы в монастыре близ колонны св. Симеона Столпника и в Пахомиевом монастыре Тавенниси. Видимо, подобные архивы имелись и при монастыре Евфимия и Великой Лавре [10, p. 353-357].

Из документов, включенных Кириллом в свои сочинения, наиболее длинным было письмо Саввы, Феодосия и монахов пустыни к императору Анастасию (Kуг. 152.21-157.23). Другие официальные письма цитировались им в иных различных местах в тексте (Kyr. 112.1$11 ; 141.8-11 ; 143.25-28 ; 193.1-6)$.

Кирилл также дает полное и детальное сообщение об указах Юстиниана, изданных в ответ на требования Саввы, которые обеспечили ослабление налогов и восстановление церквей, разрушенных самаритянами в ходе восстания (Kyr. 176.21-178.13). Они представлены с точностью, которая предполагает доступ к официальным документам. Они могли храниться в Иерусалиме. Возможно, Кирилл имел перед собой копию императорской конституции; ему было бы легко получить ее от патриархата для сохранения.

Сообщение Кирилла о восстании Феодосия после Халкидона и о конфликтах между монахами и императором Анастасием происходит, по всей видимости, из какого-то палестинского исторического источника (Kyr. 41.2242.10; 140.10-14; 141.16-152.15).

Таким образом, Кирилл широко использовал документы, копии которых он мог найти в Великой Лавре. Работы Кирилла предполагают серьезную разработку документов по монастырям Палестины. Знания Кирилла о событиях в истории Церкви вне Палестины показывают, что он должен был иметь доступ к документальным источникам, хранившимся где-то поблизости от Иерусалима.

Устные источники. Кирилл разделяет с другими авторами житий зависимость от монахов и других людей, которые вспоминали описанные им события, а также намерение показать своим читателям, от кого он получил свою информацию. Акцент на надежности свидетеля - способ подтверждения надежности работы как целого. Утверждение, что информация происходит от свидетеля, есть подкрепление призыва к вере. В случае основателя монастыря атрибуция материала очевидцу заверяет читателя, что книга представляет традиции, сохраненные отцами-основателями монастыря. Видимо, таким был мотив для ссылки на источники от очевидцев в «Житии Пахомия» (V. Pach. G. $\left.{ }^{1}, 10\right)$.

Кирилл был осторожен, указывая случаи, когда он сам был очевидцем событий, которые он описывал. Чудеса после смерти святых были лишь немногими из тех, которые он «увидел своими собственными глазами» (Kyr. 82.12-13). Но большинство событий «Жития Саввы» и все в «Житии Евфимия» имели место до рождения Кирилла. Для получения информации по ним он опрашивал «старейших из отцов пустыни» (Куг. 82.3183.1). Он упоминает многих из своих собеседников по имени. Наиболее важным из них был Иоанн Исихаст, который «оставил много наставительных рассказов о Евфимии и Савве» (Kyr. 105.19-20). Иоанн вступил в Великую Лавру в 491 г. - за 41 год до смерти Саввы. К его информации из первых рук о событиях жизни Саввы он мог добавить рассказы о Евфимии, которые Савва передавал ему. Длительные визиты в пустыню в течение Великого поста и в другие времена предоставляли Иоанну возможность послушать о подвигах Евфимия от Саввы (Kyr. 56.19-21). Эта информация, видимо, иногда была недостаточно полной, так как один раздел, приписываемый Иоанну, о безупречном православии Евфимия, был в большом объеме заимствован из Феодорита и Confessio Fidei Юстиниана (Kyr. 39.18-41.3). Свидетельство Иоанна здесь помещено предположительно для свидетельства о православии Евфимия.

Другим устным источником Кирилла был Кириак, который знал Евфимия, хотя он вступил в Евфимиев монастырь после 475 г., через два года после смерти святого (Kyr. 225.22-25). Кирилл посещал Кириака несколько раз. Он говорит нам о двух из этих визитов и о том, что Кириак был готов рассказывать ему о Евфимии и Савве (Kyr. 229.810;232.3-10; 231.22-25; 232.14-15;29.7-30.6). Эта информация Кириака оценивается как «почти прямая». Вступив в монастырь вскоре после Евфимиевой смерти, он нашел, что 
память о нем была тогда еще полностью жива, и мы видим, что даже в самой крайней старости Кириак сохранял эту память, поскольку она долго удерживалась последователями Евфимия, и, так как она научила его всему образу жизни, Кириак смог передать Кириллу в точности подлинную традицию основателя.

Среди большого числа монахов, которых Кирилл упоминал в своих сочинениях, Теребон, исцеленный от демона Евфимием, мог передать информацию о сарацинах и Палаточном Лагере (Kyr. 18.12-21, 19). Григорий был племянником Саввы и источником для некоторых рассказов о его юности (Kуг. 90.1-2). Армянин Павел, ученик Иеремии, передал Кириллу «много чудес и большинство вещей, упомянутых в этой книге» (Kyr. 105.15-16). Анастасия, жена Помпея, племянника императора Анастасия, была в Константинополе во время первого визита Саввы, а затем стала монахиней на Масличной горе в Иерусалиме (Kyr. 145.8; 147.7). Она была ценным источником информации о дипломатической стороне пастырства Саввы. Георгий, старый наставник Кирилла в Скифополе, рассказывал Кириллу о влиянии Саввы на тамошних горожан (Kуг. 164.25-27). Эти монахи передавали устные сообщения о жизни святых. В дополнение к ним мы можем принять, что деяния основателей монастырей запоминались лучше и передавались монахами из поколения в поколение. Годовщины смерти святых были поводами, когда их житие активизировалось в памяти. Указание на то, что память святого и его подвиги вспоминались в монастыре, обеспечено фрагментом «Жития Евфимия». Этот обычай мог гарантировать, что традиции о подвижниках не забывались.

Автобиографические источники. Заключительным видом источников, который использовал Кирилл, был его собственный опыт. Он повлиял на некоторые разделы его сочинений. О сходстве между сообщениями о его собственном детстве и детстве Евфимия неоднократно упоминалось [6, p. 37-38]. Видимо, в отсутствии информации о воспитании Евфимия Кирилл использовал соответствующие поучительные события из детства, основанные на его собственном опыте. Отсутствие внезапного момента обращения и медленное постижение монашеской традиции следовало модели его собственной жизни. Жития святых, которых он описывает, также следовали подобной модели (Kyr. 10.5-13.8; 86.27-88.17; 223.1-12). Единственное отклонение от стереотипа - описание молодого Кириака, охваченного решением жить в пустыне после евангельского чтения в храме, словно «пронзив-

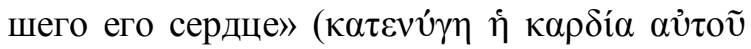

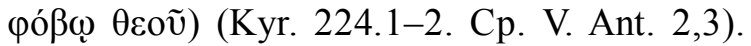
Здесь мы видим достаточно общего, чтобы увидеть самого автора, переносящего собственный опыт на его объект. Персонажи Кирилла, как и он сам, были юношами, рано развившими у себя благочестие.

Выводы. Кирилл не был единственным монахом Палестины VI в., который писал о святых. Мы знаем и другие произведения, которые происходили из монастырей, кое-что добавляют к нашим знаниям и написаны с позиций, отличающихся от убеждений Кирилла. Тем не менее именно жития, написанные Кириллом Скифопольским, дают нам наиболее яркую картину монашеской жизни Палестины VI в., особенно Иудейской пустыни. Источники Кирилла были достаточно разнообразны, а их использование позволяет сделать вывод о разумной степени заимствования, не искажающей достоверности большинства сообщаемых исторических сведений.

\section{ПРИМЕЧАНИЯ}

${ }^{1}$ Евагрий Понтийский (ок. 345-399 гг.) разделял некоторые идеи Оригена, и был предан вместе с ним анафеме в 533 г. на V Вселенском соборе.

${ }^{2}$ О Евагриевом влиянии на Палладия см.: [8, p. 351-364].

${ }^{3}$ Кириак умер на 107-й год своей жизни, а родился 8 января 449 г. (Куr. 223.5-6; 234.30). Следовательно, он умер в конце 556 или в первые несколько дней 557 года.

\section{СПИСОК ЛИТЕРАТУРЫ}

1. Читти, Д. Град Пустыня. Введение в изучение египетского и палестинского монашества в христианской империи / Д. Читти. - СПб. : Библиополис, 2007. - 320 с.

2. Шелудченко, Ю. В. К вопросу о жизни и трудах Кирилла Скифопольского / Ю.В.Шелудчен- 
ко // Империя ромеев во времени и пространстве : Центр и периферия. - М. ; Белгород : Эпицентр, 2016. - С. 224-225.

3. Шелудченко, Ю.В.Кирилл Скифопольский, его происхождение и образование / Ю. В. Шелудченко // Классическая и византийская традиция. 2017. - Белгород : Изд-во БелГУ, 2017. - С. 320-329.

4. Шелудченко, Ю. В. Христианская церковь ранневизантийского Скифополя / Ю. В. Шелудченко // Научные ведомости БелГУ. Серия: История. Политология. - 2017. - № 8 (257), вып. 42. - С. 46-50.

5. Binns, J. Ascetics and ambassadors of Christ : The monasteries of Palestine, 314-631 / J. Binns. Oxford : Oxford University Press, 1994. - 388 p.

6. Chitty, D. J. The desert a city / D. J. Chitty. Oxford : Oxford University Press, 1966. - 366 p.

7. Diekamp, Fr. Die origenistischen Streitigkeiten im sechsten Jahrhundert und das fünfte allgemeine Concil / Fr. Diekamp. - Münster : AG Verlag, 1899. $455 \mathrm{~S}$.

8. Draguet, R. L'histoire lausiaque, une oeuvre écrite dans l'esprit d'Évagre / R. Draguet // Revue d'histoire ecclésiastique. - 1946. - № 41. - P. 351-364.

9. Elliott-Binns, J. Cyril of Scythopolis and the monasteries of the Palestinian desert / J. Elliott-Binns. L. : King's College, 1989. - 288 p.

10. Festugiere, A.-J. Antioche païenne et chrétienne / A.-J. Festugiere. - Paris : Les belles lettres, 1959. $-362 \mathrm{p}$.

11. Perrone, L. La chiesa di Palestina e le controversie cristologiche / L. Perrone. - Brescia : Tosca, 1980. - 374 p.

12. Petersen, J. M. The Dialogues of Gregory the Great in their late antique cultural background / J. M. Petersen. - Toronto : Flames, 1984. - 262 p.

13. Regnault, L. Les Apophtegmes des pères en Palestine aux V $\mathrm{V}^{\mathrm{e}}-\mathrm{VI}^{\mathrm{e}}$ siècles / L. Regnault // Irénikon. 1981. - № 54. - P. 320-330.

14. Schwartz, E. Kyrillos von Skythopolis / E. Schwartz. - Leipzig: Teubner Verlag, 1939.-511 S.

\section{REFERENCES}

1. Chitti D. Grad Pustynya. Vvedenie v izuchenie egipetskogo i palestinskogo monashestva $v$ khristianskoy imperii [The Desert City. Introduction to the Study of Egyptian and Palestinian Monasticism in the Christian Empire]. Saint Petersburg, Bibliopolis Publ., 2007. 320 p. (in Russian).

2. Sheludchenko Yu.V. K voprosu o zhizni i trudakh Kirilla Skifopolskogo [On the Cyril of Scyphopolis' Life and Works]. Imperiya romeev vo vremeni i prostranstve: tsentr i periferiya [The Empire of the Romans in Time and Space: the Core and the Periphery]. Moscow; Belgorod, Epitsentr Publ., 2016, pp. 224-225 (in Russian).

3. Sheludchenko Yu.V. Kirill Skifopolskiy, ego proiskhozhdenie i obrazovanie [Cyril of Scyphopolis, His Origin and Education]. Klassicheskaya $i$ vizantiyskaya traditsiya. 2017 [Classical and Byzantine Tradition. 2017]. Belgorod, BelGU Publ., 2017, pp. 320-329 (in Russian).

4. Sheludchenko Yu.V. Khristianskaya tserkov rannevizantiyskogo Skifopolya [Christian Church of Early Byzantine Scyphopolis]. Nauchnye vedomosti BelGU. Seriya: Istoriya. Politologiya [Belgorod State University Scientific Bulletin. History. Political Science], 2017, no. 8 (257), iss. 42, pp. 46-50 (in Russian).

5. Binns J. Ascetics and ambassadors of Christ: the monasteries of Palestine, 314-631. Oxford, Oxford University Press, 1994. 388 p.

6. Chitty D.J. The desert city. Oxford, Oxford University Press, 1966. 366 p.

7. Diekamp Fr. Die origenistischen Streitigkeiten im sechsten Jahrhundert und das fünfte allgemeine Concil. Münster, AG Verlag, 1899. 455 p.

8. Draguet R. L'histoire lausiaque, une oeuvre écrite dans l'esprit d'Évagre. Revue d'histoire ecclésiastique, 1946, vol. 41, pp. 351-364.

9. Elliott-Binns J. Cyril of Scythopolis and the monasteries of the Palestinian desert. London, King's College, 1989. 288 p.

10. Festugiere A.-J. Antioche païenne et chrétienne. Paris, Les belles lettres, 1959. 362 p.

11. Perrone L. La chiesa di Palestina e le controversie cristologiche. Brescia, Tosca, 1980. 374 p.

12. Petersen J.M. The Dialogues of Gregory the Great in their late antique cultural background. Toronto, Flames, 1984. 262 p.

13. Regnault L. Les Apophtegmes des pères en Palestine aux $\mathrm{V}^{\mathrm{e}}-\mathrm{VI}^{\mathrm{e}}$ siècles. Irénikon, 1981, vol. 54, pp. 320-330.

14. Schwartz E. Kyrillos von Skythopolis. Leipzig, Teubner Verlag, 1939. $511 \mathrm{p}$. 


\section{ВОПРОСЫ КУЛЬТУРЫ ВИЗАНТИИ}

\section{Information about the Authors}

Yuliya V. Sheludchenko, Postgraduate Student, Department of World History, Belgorod State National Research University, Pobedy St., 85, 308015 Belgorod, Russian Federation, bolgov@bsu.edu.ru, https://orcid.org/0000-0003-3179-2402

Nikolay N. Bolgov, Doctor of Sciences (History), Professor, Head of Department of World History, Belgorod State National Research University, Pobedy St., 85, 308015 Belgorod, Russian Federation, bolgov@bsu.edu.ru, https://orcid.org/0000-0003-0478-5565

\section{Информация об авторах}

Юлия Викторовна Шелудченко, аспирант кафедры всеобщей истории, Белгородский государственный национальный исследовательский университет, ул. Победы, 85, 308015 г. Белгород, Российская Федерация, bolgov@bsu.edu.ru, https://orcid.org/0000-0003-3179-2402

Николай Николаевич Болгов, доктор исторических наук, профессор, заведующий кафедрой всеобщей истории, Белгородский государственный национальный исследовательский университет, ул. Победы, 85, 308015 г. Белгород, Российская Федерация, bolgov@bsu.edu.ru, https://orcid.org/0000-0003-0478-5565 